DOI:

Cite this as:

Irmawati, Nur L., Salim, Abdul, Himawanto, Dwi A. Developing Character Of Children With Mental Disabilities In Sport Learning. Indonesian Journal of Disability Studies (IJDS).2018: Vol. 5(2): PP 152-156.

\title{
DEVELOPING CHARACTER OF CHILDREN WITH MENTAL DISABILITIES IN SPORT LEARNING
}

\author{
${ }^{1 *}$ Nur Laily Irmawati, ${ }^{2}$ Abdul Salim, ${ }^{3}$ Dwi Aries Himawanto \\ ${ }^{1,2,3}$ Sebelas Maret University, Surakarta, Indonesia
}

\begin{abstract}
The problem of this research is the discipline of children with mental disabilities who are low on the rules that apply in schools, especially in sports learning. This study focuses on forming the discipline character of children with mental disabilities through the provision of reward and punishment on sports learning at the SLB Surakarta. This study uses classroom action research (CAR) which consists of four stages, namely (1) planning, (2) implementation, (3) observation, and (4) reflection. The research subjects were 5 students at $1^{\text {st }}$ class of children with mental disabilities. Data collection techniques used observation and interviews. The results of this study indicate that through the provision of reward and punishment can shape the character discipline in children with mental disabilities in sports learning. The recommendation of this research is that there is a need for continuous collaboration between teachers and parents in shaping the discipline character of children with mental disabilities.
\end{abstract}

Keywords: discipline; children with mental disabilities; exercise

\section{Latar belakang}

PP No. 72 Tahun 1991 bab 2 pasal 2 menyebutkan tujuan Pendidikan Luar Biasa yaitu membantu peserta didik yang menyandang kelainan fisik/mental agar mampu mengembangkan sikap, pengetahuan dan ketrampilan sebagai pribadi maupun anggota masyarakat dalam mengadakan hubungan timbal balik dengan lingkungan sosial budaya dan alam sekitar serta dapat mengembangkan kemampuan dalam dunia kerja/mengikuti pendidikan lanjutan.

Dalam Kurikulum 2013 di dalamnya telah dirumuskan secara terpadu kompetensi sikap, pengetahuan dan ketrampilan yang harus dikuasai peserta didik, juga dirumuskan proses pembelajaran dan penilaian yang diperlukan peserta didik mencapai kompetensi yang diinginkan tersebut. Kompetensi yang diharapkan dari lulusan SDLB adalah kemampuan berfikir, terampil dan bersikap sesuai dengan karakteristiknya (Ratna.2014). Pada kurikulum 2013 juga dikembangkan nilai sikap jujur, disiplin, tanggung jawab, mandiri,

* Corresponding author: Nur Laily Irmawati

irmalaily1@gmail.com

Published online at http://IJDS.ub.ac.id/

Copyright (C) 2018 PSLD UB Publishing. All Rights Reserved santun, peduli, percaya diri, patuh terhadap tata tertib, kasih sayang, kerjasama, menghargai dan lain-lain. Dan untuk mencapai sikap atau karakter tersebut dapat dilakukan secara langsung dalam berbagai aktivitas pembelajaran yang dilakukan.

Pada umumnya sikap seseorang merupakan wujud dari pendidikan di dalam keluarga dan sekolah. Jika sejak dari dalam keluarga anak tidak dididik atau dilatih untuk hidup teratur, tertib dan menurut kemauannya sendiri maka kelak sulit diharapkan anak tersebut mampu disiplin dan mandiri, ia akan selalu tergantung pada orang lain.

Disiplin adalah ketaatan pada peraturan dan tata tertib yang ada (Solikhin \& Yulianingsih.2016). Pembiasaan hidup teratur dan mentaati peraturan akan mendorong seseorang untuk selalu siap melaksanakan tata tertib yang berlaku dan membiasakannya menjadi disiplin. Sikap disiplin yang perlu dilakukan antara lain dengan menerapkan pengetahuan dan pengertian sosial seperti mengenal hak milik orang lain, mengerti dan segera menurut untuk menjalankan kewajiban secara langsung seperti memahami aturan, mengerti tingkah laku baik dan buruk, belajar 
mengendalikan keinginan dan mengorbankan kesenangan diri tanpa peringatan orang lain (Prasojo.2014). Oleh karena itu dalam melatih kedisiplinan dibutuhkan bimbingan dan arahan dari berbagai pihak, baik dari orang tua, guru, pengasuh, maupun lingkungan sekitarnya sehingga anak dapat melakukan kegiatan sehari-hari. Mengingat intelegensi anak tunagrahita yang berada di bawah rata-rata, maka pembelajaran untuk anak tuna grahita harus disesuaikan dengan kebutuhan dan kondisi anak. Pembiasaan, pembentukan asosiasi, pemberian reinforcement, reward and punishment serta contoh-contoh konkrit akan lebih mudah diterima (Nurmeliawati.2016)

Karakteristik anak tunagrahita yang mengalami hambatan dalam kemampuan berfikir konkret dan sukar berpikir abstrak, mengalami kesulitan dalam konsentrasi, kemampuan sosialisasi terbatas, tidak mampu menyimpan intruksi yang sulit, kurang mampu menganalisis dan menilai kejadian yang dihadapi dan anak tuna grahita mampu didik prestasi tertinggi di bidang baca, tulis, hitung tidak lebih dari anak normal seting kat kelas IIIIV Sekolah Dasar (Efendi.2006) sehingga mempengaruhi sikapnya dalam kehidupan sehari-hari. Mereka cenderung bersikap sesuai keinginan sendiri dan sangat bergantung pada orang lain. Keterbelakangan mental menunjukkan fungsi intelektual di bawah ratarata secara jelas dengan disertai ketidakmampuan dalam penyesuaian perilaku dan terjadi pada masa perkembangan (Soemantri.2012). Hal itu sangat berdampak pada kedisiplinan dan kemandirian pada anak tuna grahita.

Berdasarkan fakta di lapangan, ketika pembelajaran olahraga berlangsung mereka sering terlambat dan harus menunggu orang tua mengantarkannya ke lapangan dan ketika pembelajaran berlangsung mereka cenderung berbicara dengan teman, usil dengan teman, sering ijin ke toilet dan tidak mau mengikuti pelajaran olahraga. Hal itu perlu penanganan lebih lanjut agar kelak ketika mereka berada di kelas selanjutnya dapat lebih disiplin ketika mengikuti pembelajaran olahraga. Salah satunya adalah dengan pemberian reward dan punishment. Reward adalah sesuatu yang diperoleh siswa sebagai konsekuensi dari upaya yang telah dilakukan sehingga terjadinya perubahan perilaku pada yang bersangkutan baik perilaku dalam bidang kognitif, afektif maupun psikomotorik (Sanjaya.2008). Reward diberikan untuk hal-hal baik yang dilakukannya. Pemberian reward dimaksudkan agar lebih memotivasi anak, pemberian reward dapat berupa pemberian hadiah atau simbolsimbol yang menarik maupun dalam bentuk lisan seperti mengucapkan "hebat", "bagus" dan "pintar" (Faidy.2014).

Sebaliknya jika anak melanggar aturan yang telah disepakati maka guru harus memberikan punishment. Punishment adalah penggunaan konsekuensi yang tidak menyenangkan (Suranto. 2015). Punishment dapat berupa larangan melakukan sesuatu, menegur, membentak, bermuka masam, pemberian hukuman berdiri di depan kelas, duduk terpisah dengan teman atau pemberian simbol-simbol yang kurang menarik, agar dapat membantu pembentukan asosiasi respon dan konsekuensi pada anak.

\section{Metode}

Penelitian ini menggunakan penelitian tindakan kelas (PTK), menurut Hopskin (Wiriaatmaja, 2005) penelitian tindakan kelas merupakan suatu prosedur penelitian substansif yang digunakan seseorang untuk memahami apa yang seedang terjadi sambil terlibat dalam sebuah proses perbaikan dan perubahan. penelitian Tindakan Kelas (PTK) bertujuan untuk memperbaiki dan meningkatkan proses belajar siswa, memecahkan atau mengatasi masalah dalam pembelajaran serta mencari solusi untuk memecahkan masalah tersebut melalui tindakan, meningkatkan profesionalisme tenaga pendidik dan menumbuhkan budaya akademik (Iskandar, 2012). Hal senada juga disampaikan Arikunto (2015) penelitian tindakan kelas bertujuan untuk menyelesaikan masalah melalui suatu perbuatan nyata, bukan hanya mencermati fenomena tertentu kemudian mendeskripsikan apa yang terjadi dengan fenomena yang bersangkutan. Penelitian ini dilakukan sebagai memperbaiki kondisi rendahnya kedisiplinan anak tunagrahita dalam pembelajaran olahraga dan mencari solusi untuk membangun karakter disiplin anak tunagrahita dalam pembelajaran olahraga. Adapun alur penelitian tindakan kelas menurut Arikunto (2010) adalah sebagai berikut:

Secara rinci pelaksanaan penelitian tindakan kelas ini meliputi langkah-langkah sebagai berikut: 
a. Perencanaan

Langkah-langkah yang harus dilakukan dalam tahap perencanaan oleh peneliti adalah menyiapkan perangkat pembelajaran. Instrumen penilaian berupa lembar panduan observasi untuk mengamati aktivitas siswa dalam proses pembelajaran.

b. Pelaksanaan

Tahap ini adalah pelaksanaan dari perencanaan yang telah ditetapkan. Meliputi proses pemberian disiplin dalam pembelajaran olahraga dengan menggunakan reward dan punishment.

c. Observasi

Dilaksanakan ketika proses pembelajaran berlangsung.

d. Refleksi

Meliputi kegiatan analisis akhir pembelajaran dan sekaligus menyusun rencana perbaikan pada siklus berikutnya.

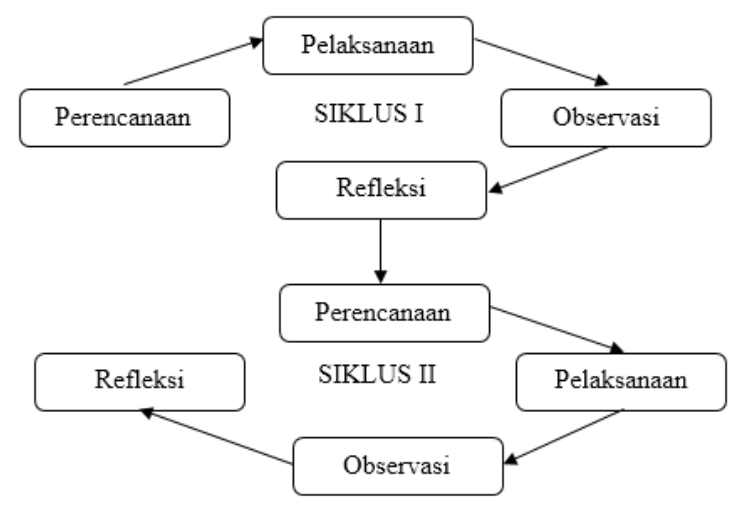

Gambar 1. Siklus Penelitian Tindakan Kelas

Dalam penelitian tindakan kelas ini, guru sebagai peneliti bertanggung jawab dan terlibat secara penuh dalam perencanaan, tindakan, observasi dan refleksi pada tiap-tiapsiklusnya. Keempat tindakan tersebut saling berkaitan dan berkelanjutan. Penelitian tindakan kelas ini dilaksanakan dalam 2 siklus (tabel 1). Karena waktu tersebut dianggap mampu memenuhi kepuasan peneliti dalam mencapai hasil yang diinginkan dan mengatasi persoalan yang ada.

Penelitian ini dilaksanakan dengan memberikan perlakuan kepada subyek dengan 2 siklus. Sampel yang digunakan dalam penelitian ini adalah 5 siswa. Teknik pengumpulan data menggunakan:

1. Observasi
Observasi atau pengamatan adalah suatu kegiatan dengan memperhatikan suatu objek dengan menggunakan seluruh alat indra (Arikunto, 2006). Pengumpulan data menggunakan metode ini digunakan untuk mengamati sikap anak tunagrahita ketika proses pembelajaran olahraga berlangsung dengan menggunakan lembar observasi yang berisi penilaian skala sikap.

2. Wawancara

Wawancara adalah pertemuan dua orang untuk bertukar informasi dan ide melalui tanya jawab, sehingga dapat dikonstruksikan makna dalam suatu topik tertentu (Sugiyono, 2016). Dalam penelitian ini peneliti menggunakan wawancara terstruktur karena dalam melakukan wawancara peneliti telah menyiapkan instrument penelitian berupa pertanyaan-pertanyaan tertulis yang alternative jawabannya telah disiapkan (Sugiyono, 2016). Wawancara dilakukan terhadap orang tua anak tunagrahita dan guru kelas.

\section{Hasil Penelitian}

Sebelum tindakan yang diberikan kepada siswa tunagrahita kelas 1 , peneliti mengadakan pengamatan untuk mengetahui kondisi awal tingkat kedisiplinan anak tunagrahita dalam pembelajaran olahraga. Dari hasil pengamatan menunjukkan bahwa tingkat kedisiplinan kelima anak tunagrahita masih sangat rendah. Data awal penilaian sikap disiplin, diketahui 4 siswa memperoleh nilai di bawah 65 dan hanya 1 siswa mendapat nilai $65 \mathrm{ke}$ atas dengan tingkat ketuntasan secara klasikal sebesar $20 \%$. Data ini menunjukkan bahwa kedisiplinan siswa belum memenuhi batas tuntas yang ditetapkan $(80 \%$ dari jumlah siswa mendapat nilai 65 ke atas). Dengan demikian, pada kondisi awal kedisiplinan siswa dapat dikatakan belum mencapai tujuan yang diharapkan.

Oleh karena itu peneliti menerapkan metode pemberian reward dan punishment dalam pembelajaran olahraga yang diterapkan dalam siklus pertama dan siklus kedua. Pada siklus pertama peneliti memberikan reward berupa kata-kata pujiandan tepuk tangan, sedangkan punishment berupa ekspresi tidak sedih atau tidak suka. Berdasarkan hasil 
penilaian sikap pada siklus I, diketahui 3 siswa memperoleh nilai di bawah 65 dan terdapat 2 siswa mendapat nilai $65 \mathrm{ke}$ atas dengan tingkat ketuntasan secara klasikal sebesar $40 \%$. Data ini menunjukkan bahwa kedisiplinan anak tunagrahita belum memenuhi siklus I, tingkat kedisiplinan dapat dikatakan belum mencapai batas tuntas yang ditetapkan $(80 \%$ dari jumlah siswa mendapat nilai 65 ke atas). Dengan demikian perlu dilakukan perbaikan pada siklus II.

Pada siklus kedua ini peneliti memberikan reward berupa peralatan menulis yang disukai dan punishment dengan tidak memberikan peralatan menulis. Berdasarkan hasil penilaian sikap kedisiplinan pada siklus II, dapat diketahui bahwa kedisiplinan anak tunagrahita telah mengalami peningkatan dibanding siklus I melalui pemberian reward dan punishment dan telah memenuhi batas tuntas yang ditetapkan (80\% dari jumlah siswa mendapat nilai 65 ke atas). Dengan demikian, pada kondisi siklus II kedisiplinan anak tunagrahita dapat dikatakan telah mencapai tujuan yang diharapkan, dan guru terus memotivasi siswa agar mempertahankan dan meningkatkan kedisiplinan.

Tabel 2. Nilai Kedisiplinan di Setiap Siklus

\begin{tabular}{|c|c|c|c|c|}
\hline No. & Subyek & $\begin{array}{c}\text { Nilai } \\
\text { Awal }\end{array}$ & $\begin{array}{c}\text { Siklus } \\
\text { I }\end{array}$ & $\begin{array}{c}\text { Siklus } \\
\text { II }\end{array}$ \\
\hline 1 & ZLV & 70 & 80 & 80 \\
\hline 2 & DMS & 40 & 50 & 70 \\
\hline 3 & VCK & 40 & 50 & 80 \\
\hline 4 & ARN & 60 & 70 & 80 \\
\hline 5 & VLT & 30 & 30 & 60 \\
\hline \multicolumn{2}{|c|}{ Jumlah } & 240 & 280 & 370 \\
\hline \multicolumn{2}{|c|}{ Rata-rata } & 48 & 56 & 74 \\
\hline \multicolumn{2}{|c|}{ Percentase } & $20 \%$ & $40 \%$ & $80 \%$ \\
\hline
\end{tabular}

Tabel 1. Dua siklus dalam penelitian kelas

\begin{tabular}{|c|c|c|c|c|}
\hline \multirow{2}{*}{ Siklus } & \multicolumn{4}{|c|}{ Kegiatan } \\
\hline & Perencanaan & Pelaksanaan & Observasi & Refleksi \\
\hline I & $\begin{array}{l}\text { - Menyusun } \\
\text { perencanaan } \\
\text { pembelajaran } \\
\text { - Menyiapkan } \\
\text { materi } \\
\text { - Menyiapkan } \\
\text { lembar } \\
\text { observasi }\end{array}$ & $\begin{array}{l}\text { Memberikan } \\
\text { penjelasan tentang } \\
\text { pemberian reward } \\
\text { dan punishment } \\
\text { dalam pembelajaran } \\
\text { olahraga dengan } \\
\text { menggunakan kata- } \\
\text { kata }\end{array}$ & $\begin{array}{l}\text { Mengamati } \\
\text { perilaku siswa } \\
\text { ketika } \\
\text { pembelajaran } \\
\text { berlangsung }\end{array}$ & 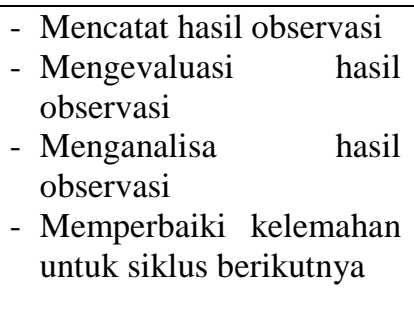 \\
\hline II & 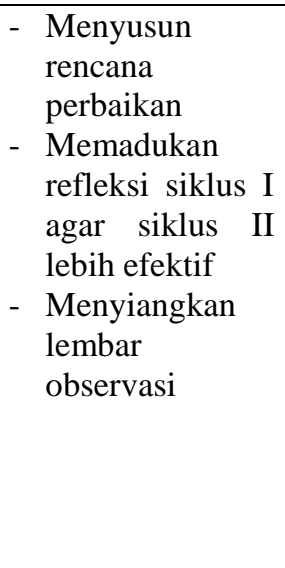 & 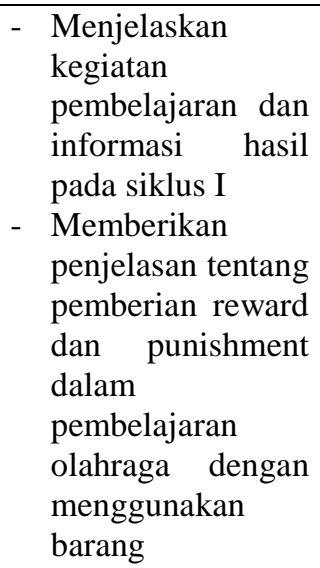 & $\begin{array}{l}\text { Mengamati } \\
\text { perilaku siswa } \\
\text { ketika } \\
\text { pembelajaran } \\
\text { berlangsung }\end{array}$ & 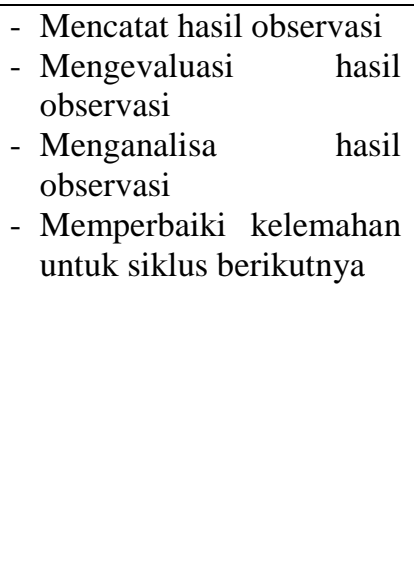 \\
\hline
\end{tabular}




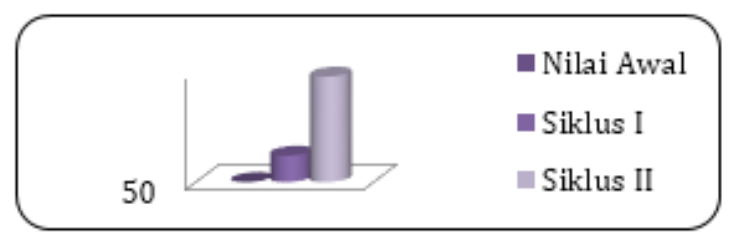

Gambar 2. Nilai Kedisiplinan di Setiap Siklus

\section{Pembahasan}

Berdasarkan hasil pengamatan menunjukkan bahwa rerata nilai sikap kedisiplinan telah mencapai nilai rata-rata 74 dari 5 siswa terdapat 4 siswa mendapat nilai di atas 65 dan tinggal 1 siswa yang mendapat nilai di bawah 65 tetapi dilihat dari nilai sikap kedisiplinan telah mengalami peningkatan yang signifikan. Ketuntasan secara klasikal sebesar $80 \%$ siswa mendapat nilai $65 \mathrm{ke}$ atas yang dapat diasumsikan indikator kinerja secara klasikal telah mencapai batas tuntas.

Berdasarkan hasil penelitian tindakan kelas hipotesis tindakan yang diajukan yang berbunyi "Melalui pemberian reward dan punishment dapat membentuk karakter disiplin pada anak tunagrahita" diterima kebenarannya, semakin konsisten guru menerapkan pemberian reward dan punishment maka semakin meningkat pula kedisiplinan anak tunagrahita.

\section{Kesimpulan}

Kesimpulan dari penelitian ini adalah (a) karakter disiplin anak tunagrahita dapat dibentuk melalui pemberian reward dan punishment (b) perlu adanya kerjasama antara guru dan orang tua dalam pemahaman dan pemberian reward dan punishment secara konsisten agar pembentukan karakter disiplin terus terjaga dan meningkat.

\section{Daftar Pustaka}

Ali Mohammad dan Asori Mohammad. (2014). Psikologi Remaja. Jakarta :Bumi Aksara.

Arikunto Suharsimi. (2010). Penelitian Tindakan Untuk Guru, Kepala Sekolah dan Pengawas. Yogyakarta. Aditya Media.

Chaplin C.P. (1995). Kamus Lengkap Psikologi.
Jakarta: Sinar Grafika.

Desmita. (2010). Psikologi Perkembangan. Bandung: PT. Remaja Rosdakarya.

Effendi, M. (2006). Pengantar Psikopedagogik Anak Berkelainan. Jakarta :Bumi Aksara.

Faidy Bahril Ahmad. (2014). Hubungan Pemberian Reward dan Punishment dengan Motivasi belajar Pendidikan Kewarganegaraan Siswa Kelas XI SMA Negeri I Ambuten Kabupaten Sumenep. Jurnal Kajian Moral dan kewarganegaraan Nomor 2 Volume 2 Tahun 2014. Halaman 454-468.

Iskandar, A. (2012). Panduan Penelitian Tindakan Kelas bagi Guru. Jakarta: Bestari.

Monks, F.J., Knoer A.M.P., dan Siti Rahayu Haditono. (1989). Psikologi Perkembangan: Pengantar dalam Berbagai Bagiannya. Yogyakarta: Gajah mada University Press.

Nurmeliawati Tia. (2016). Modul Guru Pembelajar SLB Tuna Grahita Kelompok Kompetensi B. Bandung. PPPPTK\&PLB.

Peraturan Pemerintah Republik Indonesia Nomor 72 Tahun 1991 Tentang Pendidikan Luar Biasa. Diakses tanggal 1 September 2016 dari

http://hukum.unsrat.ac.id/pp/pp199172.htm.

Prasojo Jazib Retmono. (2014). Pengaruh Perhatian Orang Tua Dan Kedisiplinan Belajar Terhadap Prestasi Belajar Mata Pelajaran IPS. Jurnal Pendidikan Ekonomi.Volume 2 No 1.Hal $1-11$.

Ratna Djuwita Rini. (2014). Lingkungan Sekolahku Tema I. Buku Tematik Terpadu Kurikulum 13.Jakarta: Kementrian Pendidikan dan Kebudayan.

Soemantri, S. (2012). Psikologi Anak Luar Biasa.Bandung:Refika Aditama.

Solikhin Firdaus M. dan Yulianingsih Wiwin. (2016). Kamus Hukum Kontemporer. Jakarta. Sinar Grafika Ofset.

Suranto. (2015). Teori Belajar dan Pembelajaran Kontemporer. Yogyakarta: Laksbang Pressindo.

Wiriaatmaja. (2005). Metode Penelitian Tindakan Kelas. Bandung: Remaja Rosdakarya. 